\title{
1 Interpolation algorithm ranking using cross-validation 2 and the role of smoothing effect. A coal zone example
}

3 Oriol Falivene ${ }^{1,3}$, Lluís Cabrera ${ }^{1}$, Raimon Tolosana-Delgado ${ }^{2}$, Alberto Sáez $^{1}$

$4{ }^{1}$ Geomodels Institute. Group of Geodynamics and Basin Analysis. Dept. EPGM. Universitat de Barcelona, c/ Martí i

5 Franquès s/n, Facultat de Geologia, 08028, Barcelona, Spain. email: oriolfalivene@ub.edu

$6 \quad{ }^{2}$ Laboratory of Marine Engineering, Technical University of Catalunya, 08034 Barcelona (Spain)

$7 \quad{ }^{3}$ Presently at Shell International Exploration and Production, Kessler Park 1, 2280 AB, Rijswijk (The Netherlands).

8 Email addres: oriol.falivene@shell.com

9 Corresponding Author: Oriol Falivene

\section{ABSTRACT}

11 For a property measured at several locations, interpolation algorithms provide a

12 unique and smooth function yielding a locally realistic estimation at any point within

13 the sampled region. Previous studies searching for optimal interpolation strategies by

14 measuring cross-validation error have not found consistent rankings; this fact was

15 traditionally explained by differences in the distribution, spatial variability and sampling

16 patterns of the datasets. This article demonstrates that ranking differences are also

17 related to interpolation smoothing, an important factor controlling cross-validation

18 errors that was not considered previously. Indeed, smoothing in average-based

19 interpolation algorithms depends on the number of neighbouring data points used to

20 obtain each interpolated value, among other algorithm parameters. A 3D dataset of

21 calorific value measurements from a coal zone is used to demonstrate that different

22 algorithm rankings can be obtained solely by varying the number of neighbouring points

23 considered (i.e. whilst maintaining the distribution, spatial variability and sampling

24 pattern of the dataset). These results suggest that cross-validation error cannot be used

25 as a unique criterion to compare the performance of interpolation algorithms, as has 
26 been done in the past, and indicate that smoothing should be also coupled to search for

27 optimum and geologically realistic interpolation algorithms.

28 Keywords: interpolation, cross-validation, smoothing effect, Kriging, inverse distance

29 weighting

\section{1. INTRODUCTION}

31 Interpolation algorithms aim to predict the value of a property at a location by

32 using values of the same property sampled at scattered neighbouring points (Journel and

33 Huijbregts, 1978; Jones et al., 1986; Davis, 2002). These algorithms yield a unique

34 (though different for each method) property map honouring input data. Interpolation in

35 geosciences is widely used for both predictive and visualization purposes. A variety of

36 algorithms have been developed to carry out interpolations (Morrisson, 1974), for

37 example inverse distance weighting (IDW, Kane et al., 1982), Kriging, (Matheron,

38 1963), splines (Ahlberg et al., 1967; Mitasova and Mitas, 1993) or polynomial

39 regression.

40 The selection of optimal interpolation strategies for continuous variables is an

41 important and ongoing subject of debate (Lu and Wong, 2008; Bater and Coops, 2009).

42 Cross-validation (CV) has often been used to compare the performance of interpolation

43 algorithms (Table 1). CV is based on calculating the value of the variable at locations

44 where the true value is known, but has been temporally removed from the input data,

45 and then measuring the CV error by comparing the estimated value against the true one

46 (Davis, 1987; Isaaks and Srivastava, 1989). Past comparisons based on CV error have

47 yielded a variety of results, not always consistent (Table 1). For instance, in comparison

48 of two widely used algorithms such as Kriging and IDW, some authors have found that

49 Kriging yields better interpolations (Weber and Englund, 1994; Zimmerman et al., 
50 1999; Goovaerts, 2000; Teegavarapu and Chandramouli, 2005; Lu and Wong, 2008),

51 some have not found any significant differences in the results (Dirks et al., 1992;

52 Moyeed and Papritz, 2002; Gallichand and Marcotte, 1993), and others have found that

53 IDW yields better interpolations (Weber and Englund, 1992; Lu and Wong, 2008).

\section{TENTATIVE POSITION FOR TABLE 1}

55 The disparity in the results obtained from existing interpolation algorithm 56 rankings using $\mathrm{CV}$ error (Table 1) motivated this research. We demonstrate that the 57 comparisons solely based on CV error are utterly flawed. Apart from the fact that 58 rankings may depend on some specific characteristics of the particular data set used for

59 the comparison, we provide evidence that the size of the search neighbourhood plays a 60 determinant role in algorithm rankings considering only $\mathrm{CV}$ error. The search 61 neighbourhood is amongst the factors controlling the smoothing effect of each 62 interpolation strategy. These findings challenge the practice of ranking and qualifying 63 interpolation algorithms considering CV error (Table 1), and show that there is no 64 absolute best interpolation algorithm: one has to establish a trade-off between minimum

$65 \mathrm{CV}$ error and predictions with low smoothing. A representative example, derived from a 66 real 3D dataset with calorific values from a coal mine, is used for illustration purposes 67 (Figure 1).

\section{TENTATIVE POSITION FOR FIGURE 1}

69 2. METHODS

70 For our rankings, we considered two commonly used interpolation algorithms:

71 IDW and Ordinary Kriging. Both methods provide an estimate $Z^{*}$ of the studied variable 
$72 Z\left(x_{0}\right)$ at an unsampled location $x_{0}$, by means of a linear combination of $N$ observed

73 values of $Z$, denoted as $z_{1}, z_{2}, \ldots, z_{N}$,

$$
Z^{*}\left(x_{0}\right)=\Sigma w_{i} \cdot z_{i}
$$

74 For both algorithms compared, several numbers of averaged neighbours, $N$, 75 ranging from 1 (nearest neighbour) to 288 were considered. Apart from well data 76 locations (Figure 1B), interpolations were also carried out over the whole three77 dimensional grid (Figure 1D) to attach a visual representation to the interpolation 78 strategies compared by $\mathrm{CV}$.

IDW is a straightforward and simple interpolation method, in which the weights $80 w_{i}$ of Eq. (1) for each averaged neighbouring data point are assigned according to an 81 inverse of distance criterion (Kane et al., 1982).

$$
w_{i}=\beta^{-1} \cdot \mathrm{d}^{\alpha}\left(x_{i}, x_{0}\right), \text { where } \beta=\Sigma \mathrm{d}^{\alpha}\left(x_{\mathrm{i}}, x_{0}\right)
$$

82 Several distance weighting power factors were tested $(\alpha=1,2$ and 5$)$. For the 83 IDW interpolations the implementation in GSTAT was used (Pebesma and Wesseling, 84 1998).

Kriging is a geostatistical interpolation method in which the weights for each 86 averaged neighbouring data point are defined to minimise the estimation variance 87 (Matheron, 1963; Journel and Huijbregts, 1978; Cressie, 1990). The minimisation of 88 this variance enables a spatial covariance criterion to be introduced, which results in 89 weights for each data point that not only depend on the distance and direction to the grid 90 cell being estimated (as in IDW), but also on the characteristics of the interpolated 91 property (described by the variogram, $\mathrm{V}(h)$, Figure 2 ) and the relative positions of the 
92 averaged hard data (redundancy factor). For the Kriging interpolations the

93 implementation in GSLIB was used (Deutsch and Journel, 1998).

94 As usual, CV was carried out by temporarily removing an entire well from the 95 dataset (Deutsch, 2002), but using the model parameters derived from the exhaustive 96 dataset to execute interpolations. CV error was taken as the average of the absolute

97 differences between each predicted interpolation estimate and its corresponding real

98 value. Standard deviation of the CV estimations was used to measure interpolation

99 smoothing; their relationship is inverse (the higher the standard deviation, the lower the

100 smoothing). Reference behaviours for the CV comparisons were defined by nearest

101 neighbour interpolation, and random-based interpolation (i.e. assigning random values

102 from the input distribution (Figure 1C) considering different degrees of smoothing and 103 without considering the neighbouring data points preferentially.

\section{3. ILLUSTRATION}

\section{3.1. Dataset, interpolation grid and interpolation parameters}

106 The dataset used for illustration derives from the As Pontes Basin (NW Spain), a 107 small mined non-marine basin $\left(12 \mathrm{~km}^{2}\right)$ resulting from the activity of an Oligocene108 Early Miocene strike-slip fault system (Bacelar et al., 1988; Santanach et al., 2005;

109 Figure 1A). The sedimentary basin fill consists of a 350-400 m thick succession of 110 siliciclastic facies assemblages alternating and interfingering with coal deposits

111 (Cabrera et al., 1995, 1996; Falivene et al., 2007a, 2007b), and was extensively drilled 112 owing to coal mining interest. Lithofacies of the continuously cored exploration wells 113 were correlated, taking into account the settling and spreading of the major coal seams, 114 which are bounded by isochronous or near-isochronous surfaces. Several composite 115 sequences and intervals were identified (Ferrús, 1998; Sáez and Cabrera, 2002; Sáez et 
116 al., 2003). Dry-base calorific values sampled on coal beds in 174 wells drilled through a

11730 m-thick, on average, coal-dominated interval (named 6AW, Falivene et al., 2007a)

118 were used as the input data for the example in this study (Figure 1B and 1C). These

119 wells were drilled along a roughly square grid at a spacing of about $105 \mathrm{~m}$. Original

120 data consisted of more than 2700 calorific value analyses spread over $4000 \mathrm{~m}$ of

121 recovered core. Calorific value distribution in these coals, which form laterally

122 continuous beds of up to several hundreds of meters, is mainly influenced by the

123 amount of detritic material, and shows gradual lateral variations (Figure 1D and 1E).

124 To restore the post-depositional structural deformation (Santanach et al., 2005)

125 and allow an easier visualization of calorific value distribution, interpolations were

126 carried out with shifted vertical coordinates transforming the top of the 6AW zone to a

127 horizontal datum. A grid layering combining proportional and parallel-to-the-top

128 layering schemes was designed to mimic paleodepositional surfaces, along which

129 calorific values and facies display the largest continuity (Figure 1D). Horizontal grid

130 spacing was set to $20 \mathrm{~m}$. Vertical cell thickness was approximately $0.15 \mathrm{~m}$, in line with

131 the resolution of core descriptions. Calorific values measured in the cores were upscaled

132 to the size of grid cells by arithmetic averaging (Figure 1C), which averaged variability

133 at smaller scales than the cell size. Upscaled calorific values measured in the coal beds

134 were then transformed to normal distribution using a normal-scores transformation

135 (Deutsch and Journel, 1998). The transformed data were the input for further analyses.

136 Parameters required for interpolation algorithms (i.e. variogram parameters for

137 Ordinary Kriging and vertical-to-horizontal anisotropy ratios for IDW) were adjusted

138 from the complete dataset (Figure 2). Anisotropy ratio (Jones et al., 1986; Falivene et

139 al., 2007a) for IDW was approximated by the vertical-to-horizontal variogram range 
140 ratio. This factor is used to multiply the vertical coordinates prior to the interpolation in

141 order to deal with geometric anisotropy (Kupfersberger and Deutsch, 1999). This

142 enables assigning different weights to hard data points located at the same real distance

143 from the point being estimated, but with different stratigraphic position, and allows

144 reproducing flattened geometries, which are typical of sedimentary deposits.

145 TENTATIVE POSITION FOR FIGURE 2

\section{$146 \quad$ 3.2. Results}

147 Results were computed directly both for the normal property and after undoing 148 the normal scores transformation to the original data scale. As both results are

149 qualitatively similar, for simplicity and geological relevance only the back-transformed

150 results are shown (Figure 3, 4 and 5). Results in Figure 3 can be summarized as:

151 1) CV error is not independent of smoothing; for random-based interpolation, as

152 smoothing increases, CV error decreases (Figure 3). Nearest neighbour interpolation 153 yields the largest CV error and the lowest smoothing with respect to Kriging and IDW 154 (Figure 3).

155 2) Compared to the results of random-based interpolation, by using average156 based interpolation methods, the CV error and smoothing are always smaller (Figure 3).

157 3) When a small number of neighbouring data points are considered (Figure 4A 158 and $\mathrm{B}$ ), the largest $\mathrm{CV}$ errors are obtained (Figure 3). If the number of neighbouring 159 data points increases (Figure 4C and D), then CV error decreases (Figure 3). In IDW, 160 for very large numbers of neighbouring points, CV error increases slightly. 

et al., 1993, Figure 3).

5) For IDW, on increasing the power factor, smoothing decreases, whereas CV

164 error tends to increase (Figure 3B and C). Increasing the power factor increases the 165 importance of the nearest samples, thus effectively reducing the number of influential 166 samples in the neighbourhood.

167 6) Depending on the degree of interpolation smoothing (i.e. on the number of 168 neighbours considered for interpolation), completely different algorithm rankings can be 169 obtained if only CV error is taken into account (Figure 3B and C).

\section{DISCUSSION AND CONCLUSIONS}

An optimal interpolation algorithm should provide minimum cross-validation

$174(\mathrm{CV})$ error, as is common practice in the literature (Table 1). CV errors in the example 175 presented here range between 10 to $15 \%$ of the mean measured calorific value (Figure 176 3). These variations are large enough to rank the different algorithms, and can be 177 significant when predictions are made over large coal volumes. In addition, an optimal 178 interpolation algorithm should also obtain results with relatively low interpolation 179 smoothing (Isaaks and Srivastava, 1989; Olea and Pawlowsky, 1996; Journel et al., 180 2000), which seeks to preserve as much as possible the gradual lateral variation of 181 calorific values shown in the mine (Figure 1D, compare Figure 4A to 4C, and 4B to 4D, 182 Figure 5). 
185 error (Table 1) have been traditionally justified by the fact that the studied variables are

186 characterized by different histogram distributions, spatial continuity or sampling 187 patterns (Brummert et al., 1991; Zimmerman et al., 1999; Lu and Wong, 2008). For

188 example, a general consensus exists that, in irregularly spaced data, Kriging should

189 provide more accurate and robust results than IDW, because Kriging takes into account

190 the relative positions of sampling points, and not only their distance from the

191 interpolated point (Kane et al., 1982; Lebel et al., 1987; Weber and Englund, 1994;

192 Borga and Vizzacaro, 1997; Goovaerts, 2000; Falivene et al., 2007a).

193 The results shown herein demonstrate that, if only CV error is considered, 194 different algorithm rankings can be obtained by changing the number of neighbours 195 averaged (Figures 3B and 3C). Thus, differences in algorithm rankings cannot be fully 196 explained by intrinsic differences related to the variable studied and the sampling 197 patterns, as suggested before. Indeed, interpolation smoothing partially controls the 198 results of $\mathrm{CV}$ error (Figure 3). Interpolation smoothing is primarily controlled by the 199 number of neighbours averaged, but also by the algorithm itself and other algorithm 200 parameters (e.g. the semivariogram in kriging and the anisotropy ratio and the power 201 factor in inverse distance weighting).

202 As a consequence, using only CV error as ranking criteria provides ambiguous 203 results, because smoothing (relating to each particular algorithm and algorithm 204 parameters) heavily influences the CV rankings and the appearance and continuity of 205 the interpolation results (Figure 4 and 5). The interpolation results obtained with the 206 largest number of neighbours are the ones that yield the lowest CV error, but Figure 4 207 and 5 shows that the predictions between data points in these cases tend to be too 
smooth, because of the increasing influence from too much data further away.

209 Therefore, minimum CV error cannot be the unique criterion of interpolation optimality,

210 as have been used in previous studies (Table 1). Even for the same interpolation

211 method, the optimum number of neighbours averaged is not the one that yields

212 minimum CV errors because the smoothing introduced in the interpolation must also be

213 taken into account.

214 Multiple-criterion rankings, for instance coupling CV error and smoothing,

215 needs to be used to search for optimum interpolation strategies. This multi-criterion

216 would discard too smooth calorific value distributions (i.e. disconnecting large and

217 small calorific values identified in adjacent wells), such as those in Figure 4D, even

218 though they may yield the lowest CV error (Figure 3C). And it would favour gradual

219 and laterally continuous, with moderate CV error and smoothing, such as those in

220 Figure 4A or 4B (Figure 5). Therefore, in more general terms applicable to other

221 geological situations or case studies, the analyst should search for a trade-off between

222 geological continuity (low smoothing) and statistical optimality (low average CV error),

223 in order to look for best interpolation practices.

\section{5. ACKNOWLEDGEMENTS}

\section{6. REFERENCES}

234 Ahlberg, J.H., Nilson, E.W., Walsh, J.L., 1967. The theory of splines and its 235 applications. Academic Press, New York, 280 pp. 
Bacelar, J., Alonso, M., Kaiser, C., Sanchez, M., Cabrera, L., Sáez, A., Santanach, P., 1988. La Cuenca Terciaria de As Pontes (Galicia): su desarrollo asociado a inflexiones contractivas de una falla direccional. II Congreso Geológico de España, Granada, Sociedad Geologica de España 113-121.

Bater, C.W., Coops, N.C., 2009. Evaluating error associated with lidar-derived DEM interpolation. Computers and Geosciences 35, 289-300

Borga, M., Vizzaccaro, A., 1997. On the interpolation of hydrologic variables: formal equivalence of multiquadratic surface fitting and kriging. Journal of Hydrology $195,160-171$.

Brummert, A.C., Pool, S.E., Portman, M.E., Hancock, J.S., Ammer, J.R., 1991. Determining optimum estimation methods for interpolation and extrapolation of reservoir properties: a case study, in Lake, L.W., Carroll, H.B., Wesson, eds., Reservoir Characterization, pp. 445-485.

Cabrera, L., Ferrús, B., Sáez, A., Santanach, P., Bacelar., J., 1996. Onshore Cenozoic strike-slip basins in NW Spain, in Friend, P.F., Dabrio, C.J., eds., Tertiary Basins of Spain, the Stratigraphic Record of Crustal Kinematics, pp. 247-254.

Cabrera, L., Hagemann, H.W., Pickel, W., and Sáez, A., 1995. The coal-bearing, Cenozoic As Pontes Basin (northwestern Spain): geological influence on coal characteristics. International Journal of Coal Geology 27, 201-226.

Cressie, N., 1990. The origins of kriging. Mathematical Geology 22, 239-252.

Davis, B.M., 1987. Uses and abuses of cross-validation in geostatistics. Mathematical Geology 19, 241-248.

Davis, J.C., 2002. Statistics and Data Analysis in Geology. John Willey \& Sons, 638 pp.

Deutsch, C.V., 2002. Geostatistical Reservoir Modeling. Oxford, New York, 376 pp.

Deutsch, C.V., and Journel, A.G., 1998. GSLIB: Geostatistical Software Library and User's Guide, 2nd edition. Oxford University Press, New York, 350 pp.

Dirks, K.N., Hay, J.E., Stow, C.D., Harris, D., 1998. High-resolution studies of rainfall on Norfolk Island Part II: interpolation of rainfall data. Journal of Hydrology 208, 187-193.

Dubrule, O., 1984. Comparing Splines and Kriging. Computers and Geosciences 10, 327-338.

Falivene, O., Cabrera, L., Sáez, A., 2007a. Optimum and robust 3D facies interpolation strategies in a heterogeneous coal zone (Tertiary As Pontes basin, NW Spain). International Journal of Coal Geology 71, 185-208.

Falivene, O., Cabrera, L., Muñoz, J.A., P., A., Fernández, O., and Sáez, A., 2007b. Statistical grid-based facies reconstruction and modelling for sedimentary bodies. Alluvial-palustrine and turbiditic examples. Geologica Acta 5, 199-230 
Ferrús, B., 1998. Análisis de cuenca y relaciones tectónica-sedimentación en la cuenca de As Pontes (Galícia). Unpublished PhD Thesis, Barcelona, University of Barcelona (Spain), $351 \mathrm{pp}$.

Gallichand, J., Marcotte, D., 1993. Mapping clay content for subsurface drainage in the Nile Delta. Geoderma 58, 165-179.Goovaerts, P., 2000. Geostatistical approaches for incorporating elevation into the spatial interpolation of rainfall. Journal of Hydrology 228, 113-129.

Herzfeld, U.C., Eriksson, M.G., Holmund, P., 1993. On the Influence of Kriging Parameters on the Cartographic Output - A Study in Mapping Subglacial Topography. Mathematical Geology 25, 881-900.

Hutchinson, M.F., Gessler, P.E., 1994. Splines - more than just an smooth interpolator. Geoderma 62, 45-67.

Isaaks, E.J., Srivastava, R.M., 1989. An introduction to Applied Geostatistics. Oxford University Press, $561 \mathrm{pp}$.

Jones, T.J., Hamilton, D.E., Johnson, C.R., 1986. Contouring geologic surfaces with the computer. Van Nostrand Reinhold, New York, 314 pp.

Journel, A., Kyriakidis, P.C., Mao, S., 2000. Correcting the Smoothing Effect of Estimators: A Spectral Postprocessor. Mathematical Geology 32, 787-813.

Journel, A.G., Huijbregts, C.J., 1978. Mining geostatistics: Academic Press, 600 pp.

Journel, A.G., Rossi, M., 1989. When do we need a trend in kriging?. Mathematical Geology 21, 715-739.

Kane, V.E., Begovich, C.L., Butz, T.R., Myers, D.E., 1982. Interpretation of regional geochemistry using optimal interpolation parameters. Computers and Geosciences 8, 117-135.

Kupfersberger, H., Deutsch, C.V., 1999. Methodology for Integrating Analog Geologic Data in 3-D Variogram Modeling. American Association of Petroleum Geologists Bulletin 83, 1262-1278.

Lebel, T., Bastin, G., Obled, C., Creutin, J.D., 1987. On the accuracy of rainfall estimation: a case study. Water Resources Research 23, 2123-2134.

Lu, G.Y., Wong, D.W., 2008. An adaptive inverse-distance weighting spatial interpolation technique. Computers and Geosicences 34, 1044-1055.

Matheron, G., 1963. Principles of geostatistics. Economic Geology 58, 1246-1266.

Mitasova, H., Mitas, L., 1993. Interpolation by regularized spline with tension: I. Theory and implementation. Mathematical Geology 25, 641-655.

Morrison, J.L., (1974). Observed statistical trends in various interpolation algorithms useful for first stage interpolation. The Canadian Cartographer 11, 142-159. 
Moyeed, R.A., Papritz, A., 2002. An Empirical Comparision of Kriging Methods for Nonlinear Spatial Point Prediction. Mathematical Geology 34, 365-386.

Okubo, C.H., Schultz, R.A., Stefanelli, G.S., 2004. Gridding Mars Orbiter Laser Altimeter data with GMT: effects of pixel size and interpolation methods on DEM integrity. Computers and Geosciences 30, 59-72.

Olea, R., Pawlowsky, V., 1996. Compensating for estimation smoothing in kriging. Mathematical Geology 28, 407-417.

Pebesma, E.J., Wesseling, C.G., 1998. GSTAT: A program for geostatistical modelling, prediction and simulation. Computers and Geosciences 24, 17-31.

Sáez, A., Cabrera, L., 2002. Sedimentological and paleohydrological responses to tectonics and climate in a small, closed, lacustrine system: Oligocene As Pontes Basin (Spain). Sedimentology 49, 1073-1094.

Sáez, A., Inglès, M., Cabrera, L., de las Heras, A., 2003. Tectonic-palaeoenvironmental forcing of clay-mineral assemblages in nonmarine settings: the OligoceneMiocene As Pontes Basin (Spain). Sedimentary Geology 159, 305-324.

Santanach, P., Ferrús, B., Cabrera, L., Sáez, A., 2005. Origin of a restraining bend in an evolving strike-slip system: The Cenozoic As Pontes basin (NW Spain). Geologica Acta 3, 225-239.

Teegavarapu, R.S.V., Chandramouli, V., 2005. Improved weighting methods, deterministic and stochastic data-driven models for estimation of missing precipitation records. Journal of Hydrology 312, 191-206.

Weber, D.D., Englund, E.J., 1992. Evaluation and comparison of spatial interpolators. Mathematical Geology 24, 381-391.

Weber, D.D., Englund, E.J., 1994. Evaluation and comparison of spatial interpolators II. Mathematical Geology 26, 589-603.

Zimmerman, D., Pavlik, C., Ruggles, A., Armstrong, P., 1999. An experimental comparision of ordinary and universal kriging and inverse distance weighting. Mathematical Geology 31, 375-390. 


\section{FIGURE AND TABLE CAPTIONS}

338 Table 1. Summary of the results from published interpolation algorithm comparisons by 339 means of the cross-validation (CV) check.

340 Figure 1. Geological setting and dataset characteristics. (A) Present basin boundary and 341 areal extent of the studied 6AW interval. Coordinates are in kilometres; see location of 342 the basin in the upper right inset. (B) Well distribution in the 6AW interval. The 343 location of the reference section in Frames D and E and in Fig. 4 is shown. (C) Relative 344 frequency of calorific values; plotted information corresponds to the core data upscaled 345 to the size of grid cells. (D) Reference section showing upscaled calorific values in the 346 intersected wells; calorific values in lacustrine and alluvial mudstone are null. 347 Approximate paleodepositional surfaces are shown. (E) Facies distribution in the coal 348 zone obtained by using indicator Kriging with an areal trend applied to categorical 349 variables (for details, see Falivene et al., 2007a). Vertical exaggeration of Frames D and $350 \quad \mathrm{E}$ is $10 \mathrm{x}$.

Figure 2. Variograms for the transformed calorific values. Black dots, crosses and dashed curves correspond to the experimental variograms derived from upscaled well data. Grey continuous curves to the theoretical model fitted ( $\mathrm{Hr}$ and $\mathrm{Vr}$ stand for horizontal and vertical ranges, respectively): $\mathrm{V}(\mathrm{h})=0.82 \cdot \operatorname{Exp}(\mathrm{Hr}=450 \mathrm{~m}, \mathrm{Vr}=2.8 \mathrm{~m})$ $+0.18 \cdot \operatorname{Exp}(\mathrm{Hr}=60 \mathrm{~m}, \mathrm{Vr}=100 \mathrm{~m})$.

Figure 3. Interpolation smoothing (measured by the standard deviation of cross validation (CV) estimates) against mean absolute $\mathrm{CV}$ error for all the interpolation strategies compared. The greater the standard deviation, the lower the smoothing; standard deviation in the original dataset was 650. (A) Results for several numbers of averaged neighbours $(2,4,12,24,48,96,192$ and 288). Note also the results of the nearest neighbour and random-based interpolations (i.e. assigning random values from the input distribution (with different smoothing degrees), and without considering the neighbouring points. (B) Detail with the results for 12 averaged neighbours. (C) Detail with the results for 192 averaged neighbours. Note the correspondences with frames in Figure 4.

Figure 4. (A, B, C, D) Reference section and map showing calorific value distributions in coal facies obtained by different interpolation strategies. Calorific value in alluvial and lacustrine mudstone facies shown in Figure 1E is null. (E) Location of the section, the map and the input data. Note that the horizontal scale of the map and the section are not the same. If the number of averaged neighbours increases, the spatial continuity of the resultant calorific value distribution in coal facies is obscured, as the result of larger interpolation smoothing. Vertical exaggeration 10x.

Figure 5. Calorific values for those cells in the intersection of the map and the section shown section in Figure 4, obtained by different interpolation strategies. Note that too smooth interpolation methods such as Kriging or IDW with 192 averaged neighbours provide interpolations that in some cases deviate largely from the closest surrounding data due to the effect of data located further away, although they yield lower CV errors than algorithms considering a smaller number of averaged neighbours. 

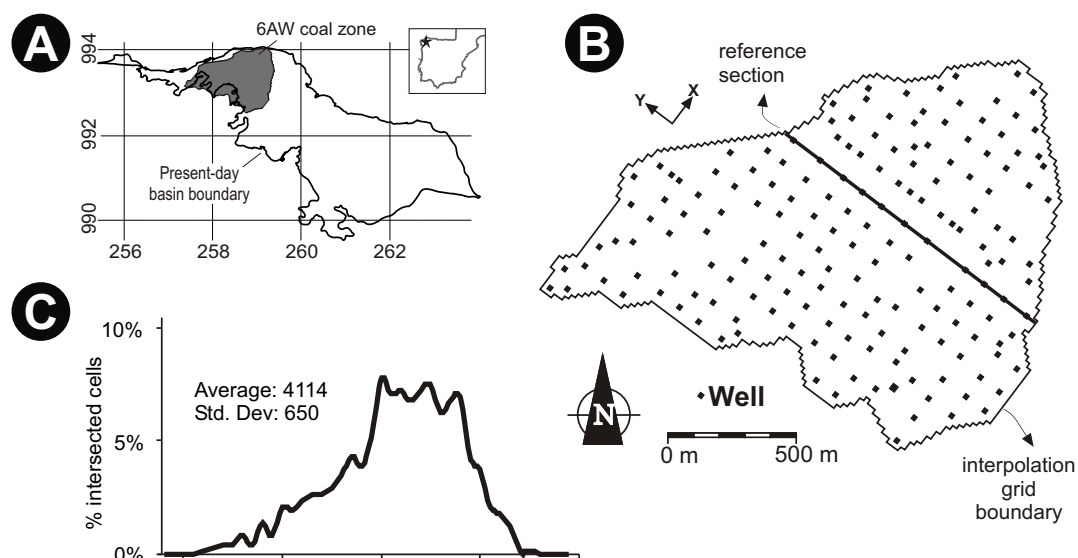

C
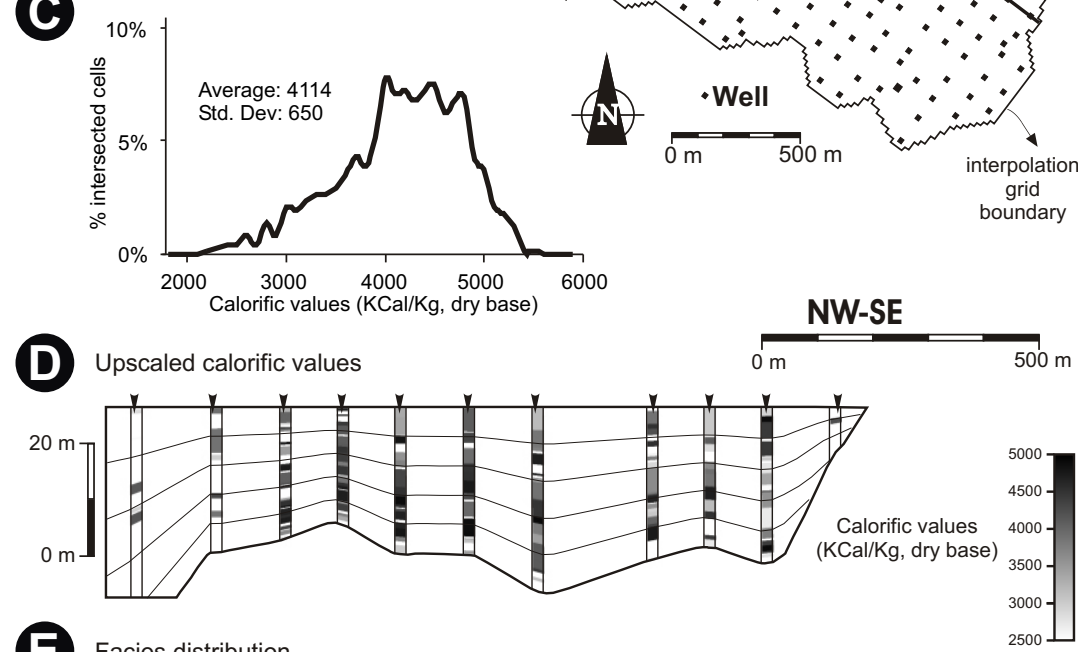

E Facies distribution

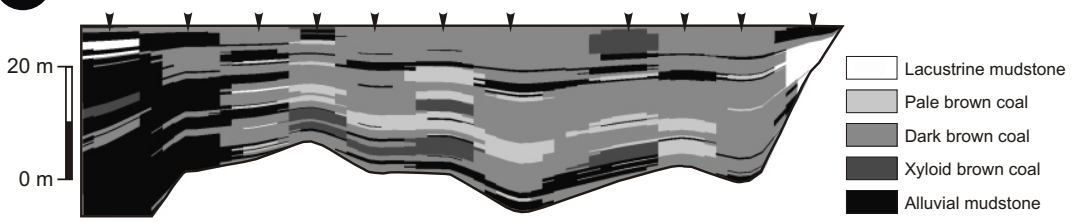

Figure 1. 

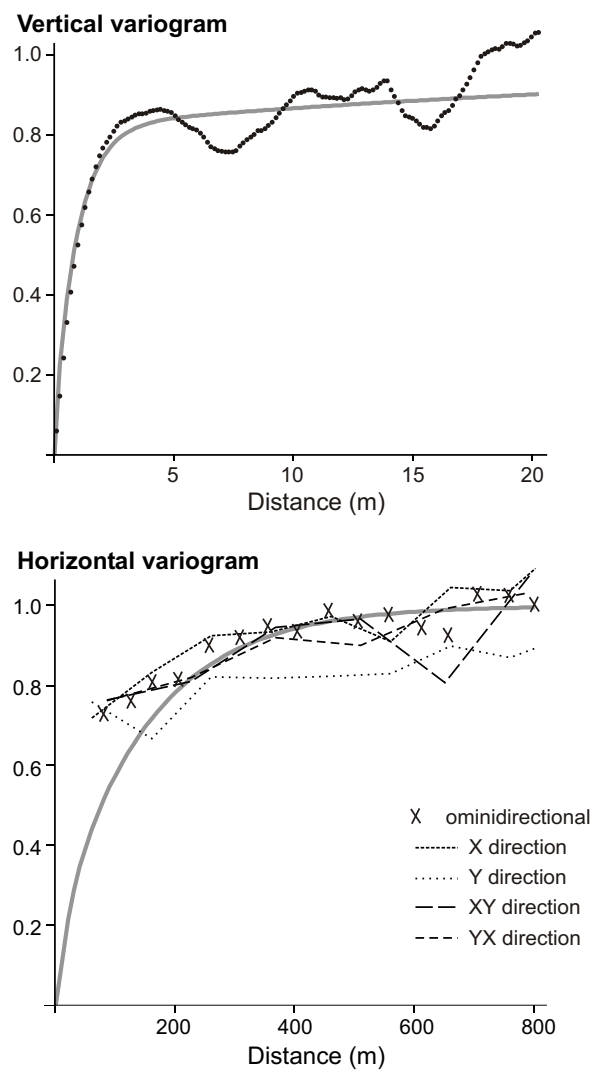

Figure 2. 


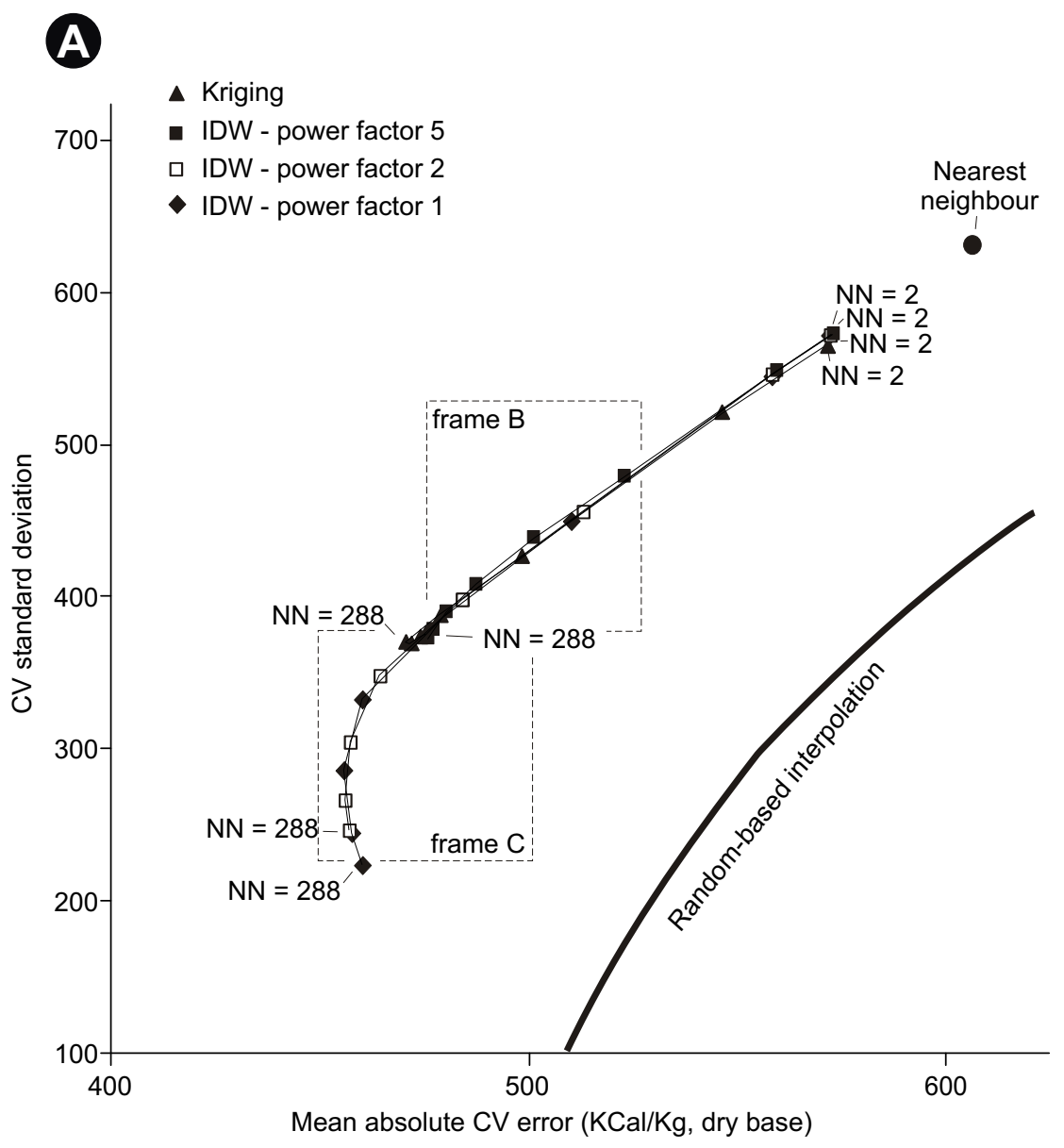

B 12 averaged neighbours

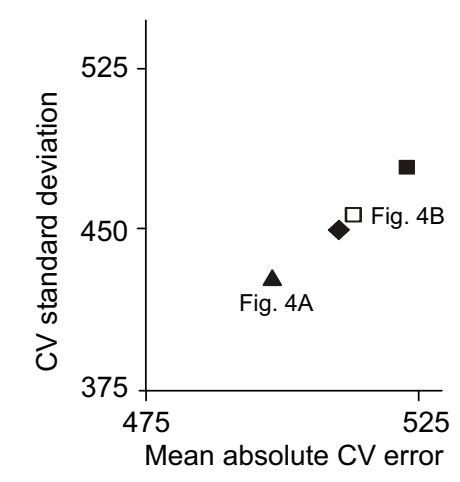

C 192 averaged neighbours

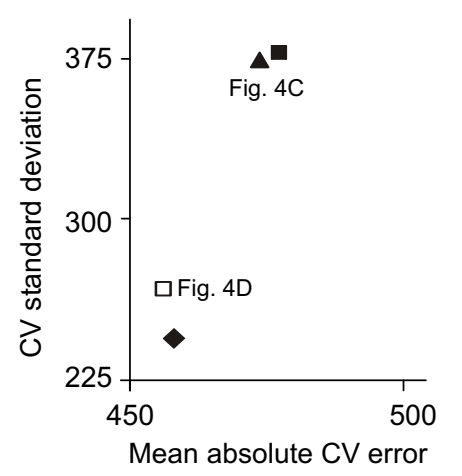

Figure 3. 
A

Kriging, 12 averaged neighbours

B IDW, power factor $=2,12$ averaged neighbours
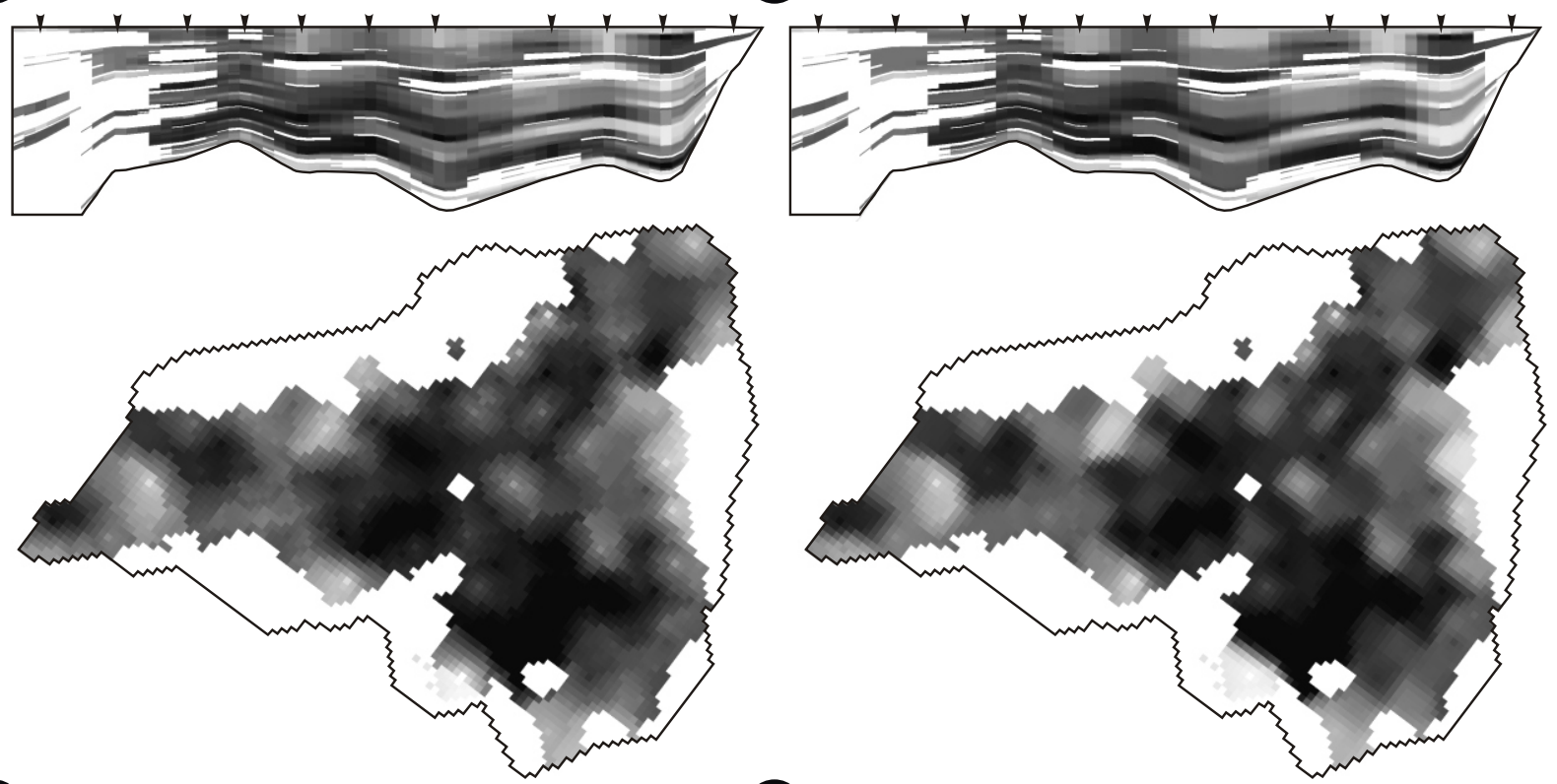

C Kriging, 192 averaged neighbours

D IDW, power factor $=2,192$ averaged neighbours
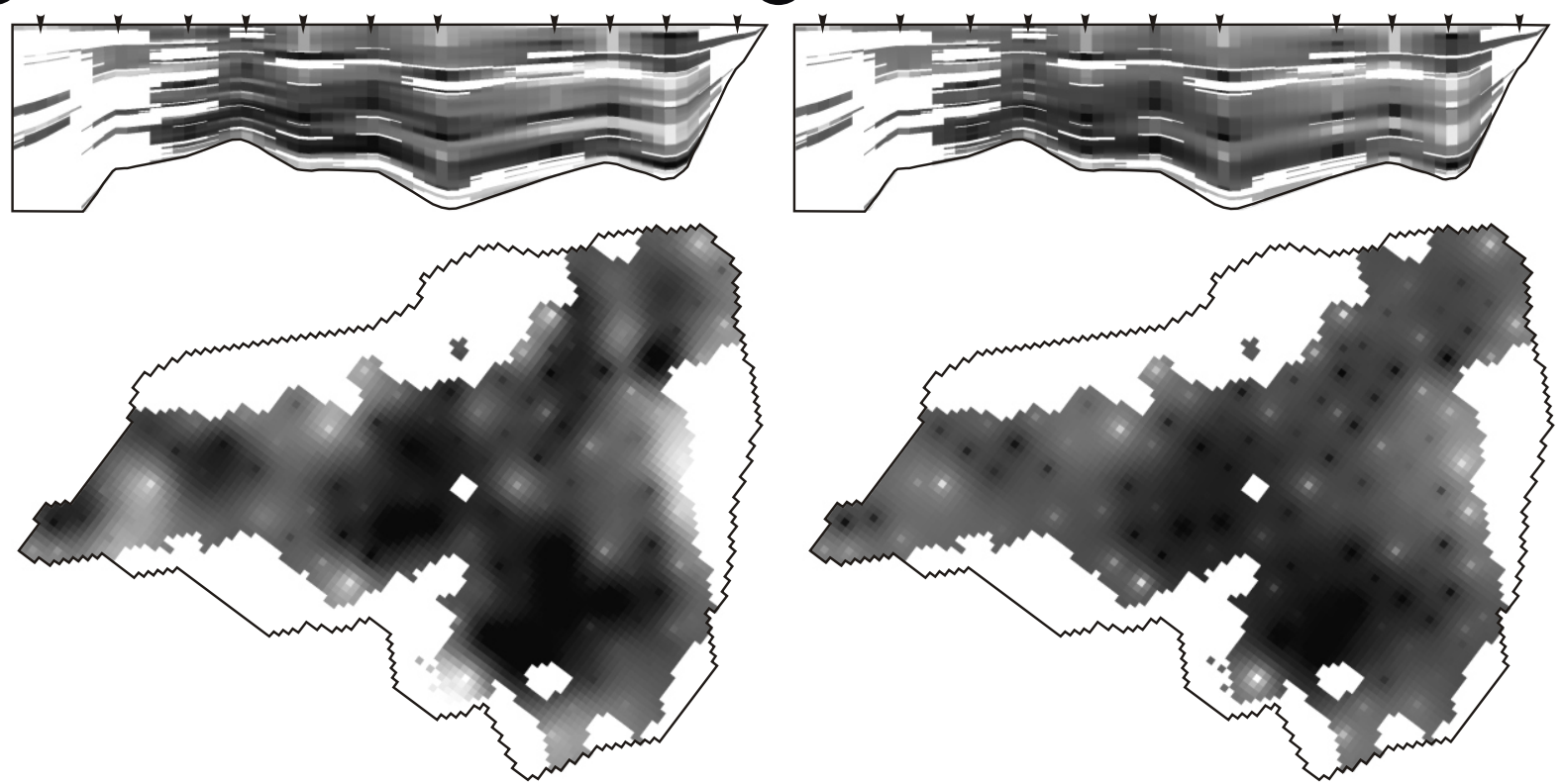

E

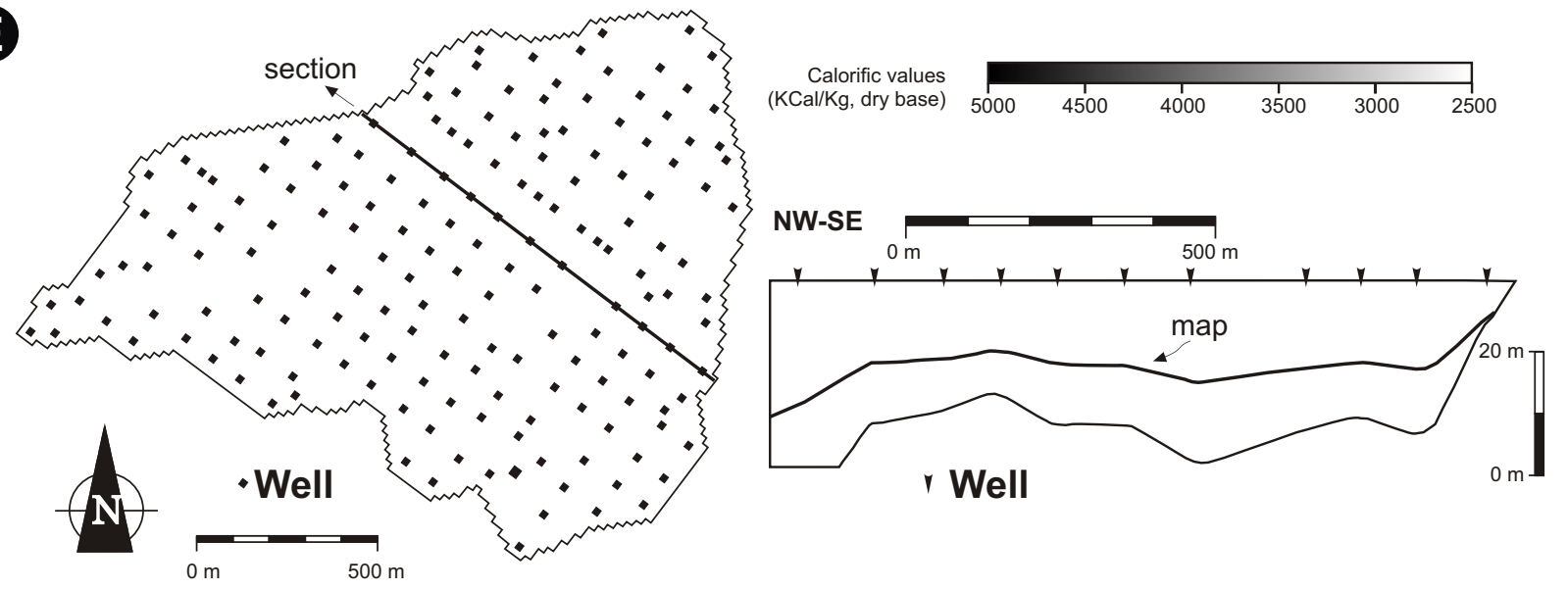

Figure 4. 


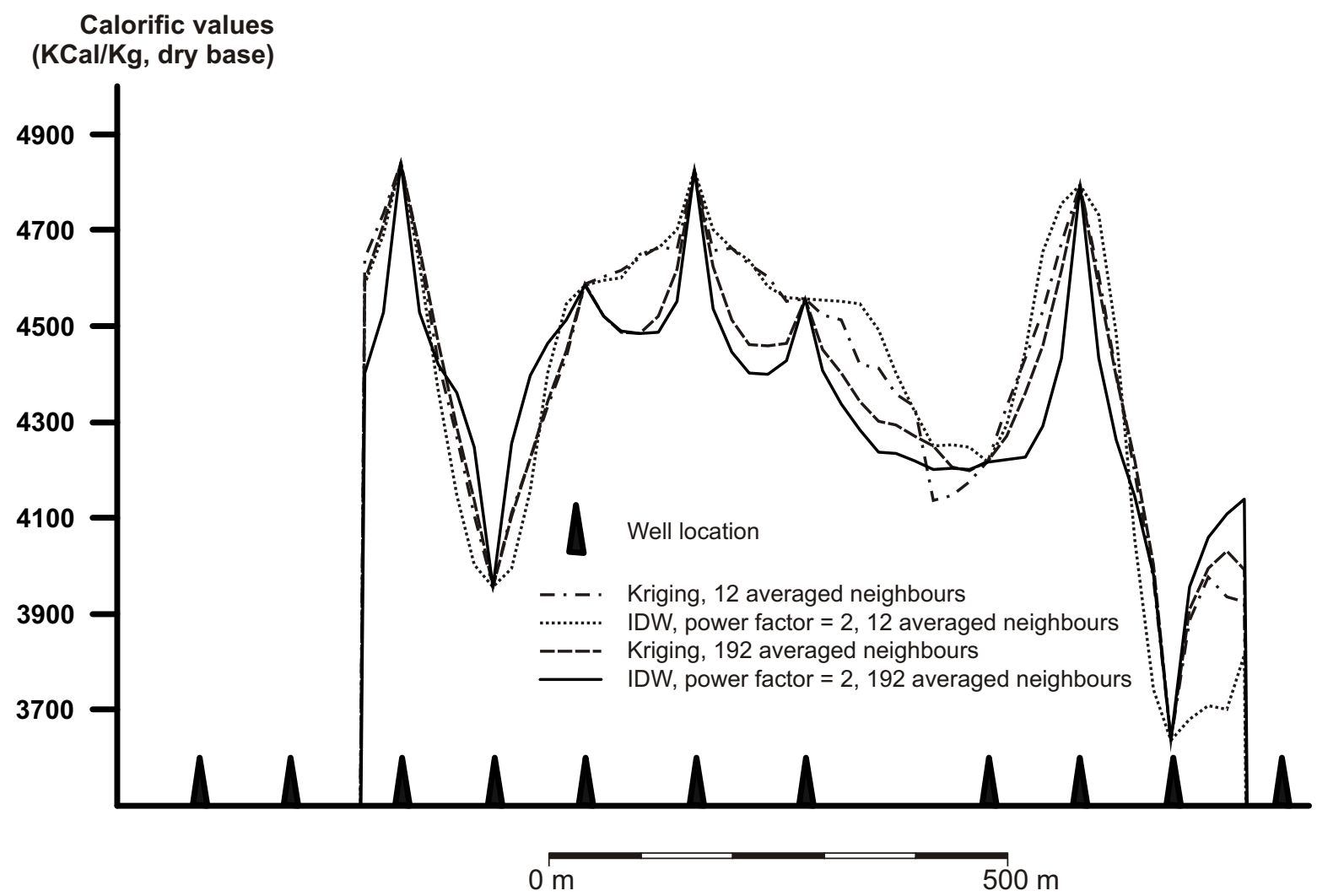

Figure 5. 
Supplementary Material Captions
Click here to download e-component: Supplementary Material Captions.doc 
Supplementary Material
Click here to download e-component: CP_IDW_012.wrl

Click here to download e-component: CP_IDW_012.wrl 
Supplementary Material
Click here to download e-component: CP_IDW_192.wrI

(

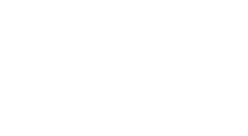


Supplementary Material
Click here to download e-component: CP_Kriging_012.wrl

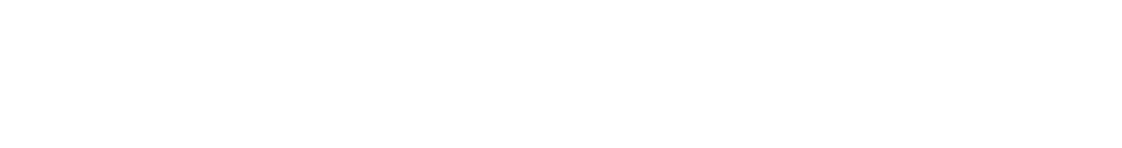

(1)

(1)

(1)

(1)

(1)

(1)

(1)

(1)

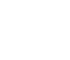

.

.

.

.

.

.

.

.

.

.

.

.

.

.

.

.

.

.

.

.

.

.

.

.

.

. 
Click here to download e-component: CP_Kriging_192.wrl Supplementary Material
Click here to download e

.

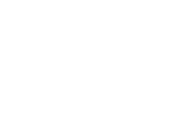

(a) 